\title{
Knowledge of the role of vaccinations, physical activity and other cancer prevention methods among Polish outpatients
}

\author{
MARTA KURCZEWSKA-MICHALAK ${ }^{A-F}$, PRZEMYSŁAW KARDASA, D, E, G \\ ORCID ID: 0000-0002-5829-6022
}

Department of Family Medicine, Medical University of Lodz, Poland

A - Study Design, B - Data Collection, C - Statistical Analysis, D - Data Interpretation, E - Manuscript Preparation, F - Literature

Search, G - Funds Collection

Summary Background. Mortality rates connected with cancer are increasing nowadays due to demographic changes in the worldwide population and the increasing number of health risks leading to cancer. Primary cancer prevention is based on avoiding exposure to identified cancer risk factors. Therefore, awareness of basic health hazards is necessary.

Objectives. The purpose of this study was to assess the knowledge of the role of vaccinations, physical activity, second-hand smoke exposure and other factors in cancer prevention in Polish outpatients.

Material and methods. This was a survey involving Polish primary care patients. The study was based on an original questionnaire designed for this purpose and was distributed among primary care patients in either hardcopy (among primary care patients in the urban settings of the city of Lodz) or over the Internet.

Results. 612 respondents took part in the study. Among the respondents, $28.4 \%$ claimed that vaccinations do not play any role in cancer prevention. Physical activity may prevent cancer according to $58.6 \%$ of the surveyed population. Tobacco smoking is a well-known cancer risk factor, which was admitted to by $97.2 \%$ of the respondents. Second-hand smoke exposure in the workplace was reported by $18.3 \%$ of the respondents, more often by those with secondary education than with a university degree. Second-hand smoke exposure was strongly connected with the age of the respondents.

Conclusions. There is little knowledge about vaccines and physical activity as cancer prevention methods. Tobacco smoking is a well-known cancer risk factor. Second-hand smoke exposure remains a serious problem in Poland despite a total ban on smoking in the workplace and public places.

Key words: preventive medicine, papillomavirus vaccines, tobacco smoke pollution.

Kurczewska-Michalak M, Kardas P. Knowledge of the role of vaccinations, physical activity and other cancer prevention methods among Polish outpatients. Fam Med Prim Care Rev 2020; 22(1): 27-31, doi: https://doi.org/10.5114/fmpcr.2020.92502.

\section{Background}

Mortality rates connected with cancer are increasing nowadays [1] due to demographic changes [2] in the worldwide population and the increasing number of health risks leading to cancer. The number of new cancer cases in Poland in 2016 was 164,140 [3]. The number of people aged 65 or older is projected to grow from an estimated 524 million in 2010 to nearly 1.5 billion in 2050, with most of the increase in developing countries [4]. It was estimated that 18.1 million (95\% UI: 17.5-18.7 million) new cancer cases and 9.6 million (95\% UI: 9.3-9.8 million) cancer deaths occurred in 2018 worldwide, and on average, there is about a $20 \%$ risk of getting cancer before the age of 75 , and there is a $10 \%$ of dying from it [5]. Therefore, awareness of basic health hazards and intervention before health effects occur, through measures such as vaccinations, altering risky behaviours (poor eating habits, tobacco use) and banning substances known to be associated with a disease or health condition are necessary. All these actions are called primary prevention [6]. Vaccinations are one of the greatest achievements of medicine, not only as protection from infectious diseases, but also as cancer prevention in particular cases. It is alarming that there have been recent trends of parents in Western countries refusing to vaccinate their children due to numerous reasons and perceived fears [7]. The HPV vaccination is recommended in Poland, but it is still quite expansive and funded only by several local governments. Not only can the HPV vaccination prevent cancer, but hepatitis B virus (HBV) immunisation, a risk factor of hepatocellular cancer, is also considered a major success in cancer prevention. Approximately 2 million new cancer cases are attributed to infectious agents each year worldwide [8].

Cervical cancer is the fourth most frequent cancer in women, with an estimated 570,000 new cases in 2018, representing $6.6 \%$ of all female cancer cases. Approximately $90 \%$ of deaths from cervical cancer occurred in low- and middle-income countries [9]. The GLOBOCAN 2012 project places Poland among countries with the highest rate of incidence and mortality due to cervical cancer, with the standardised incidence rate (SIR) at 12.2/100 000 and the standardised death rate (SDR) at 5.4/100,000 (one of the highest among the surveyed countries). Both SIR and CDR are relatively high compared to other European countries [10]. In the absence of further intervention, there would be 44.4 million cervical cancer cases diagnosed globally over the period 2020-2069. First-generation human papillomavirus (HPV) vaccines, including the quadrivalent vaccine and the bivalent vaccine, can prevent about $70 \%$ and $84 \%$ of cervical cancers, respectively. A next-generation nonavalent HPV vaccine, Gardasil 9, can prevent approximately $90 \%$ of cervical cancers. However, these vaccines do not treat pre-existing infections and related cervical abnormalities. Thus, several generations of women need effective cervical screening. In 2016, the American Society of Clinical Oncology (ASCO) released cervical screening guidelines [11] recommending screening for women aged 30-49 years one to three times per lifetime in lower-resource settings with primary HPV testing, on the basis of very strong evidence that HPV testing is a more effective, reliable and adaptable method of screening (via the use of 
self-collected specimens) than traditional cytological methods [12]. According to the European Guidelines, as well as the World Health Organization (WHO), HPV testing is now proposed as the primary screening tool for cervical cancer $[13,14]$. There are several countries in Europe and all over the world integrating HPV vaccination and population-based HPV testing in cervical cancer screening programmes [15]. Nevertheless, in Poland, the cervical cancer screening programme is based on the conventional Pap test, repeated every three years among women aged 25-69 [16].

Apart from vaccinations, the fundamental task of primary prevention is education concerning physical activity and tobacco use, as well as second-hand smoke exposure. According to many epidemiological studies and systematic reviews [17], regular physical activity is strongly correlated with reduced risks of bladder, breast, colon, endometrial, oesophageal adenocarcinoma, renal and gastric cancers. Relative risk reductions ranged from approximately 10 to $20 \%$.

Interim findings of this paper were presented at the $10^{\text {th }}$ International Congress of Internal Medicine, 22-24 March 2018 in Athens, Greece, as an oral presentation.

The first part of the research was published in 2017 in Family Medicine \& Primary Care Review: Kurczewska-Michalak M, Kardas P. The knowledge of selected cancer prevention methods among Polish outpatients. Fam Med Prim Care Rev 2017; 19(3): 235-238, doi: https://doi.org/10.5114/fmpcr.2017.69283.

\section{Objectives}

The purpose of the study was to assess the knowledge of the role of vaccinations in the prevention of certain types of cancers. Secondly, the aim of the research was to determine which foodstuffs and chemicals may lead to the development of cancer according to respondents. Furthermore, we wanted to evaluate the knowledge of physical activity as a cancer prevention method. The last objective of the survey was to assess awareness of tobacco use as a cancer risk factor, as well as exposure to second-hand smoke at work.

\section{Material and methods}

This was an open study involving primary care patients and an Internet-based survey. The study was based on an original questionnaire designed for this purpose and was distributed among primary care patients in the urban settings of Lodz, Poland, and was made available on the dedicated website over the Internet for the respondents from Poland. Data was collected in the period from September 2016 to April 2017. Patients at least 18 years of age who voluntarily agreed to participate in the study were eligible for the research. The questionnaire consisted of 40 questions, of which 10 were open questions, and the remaining were multiple choice questions. The possible answers for multiple choice questions were: 'yes', 'no' and 'hard to say'. The open questions were listed under groups of frequency. Quantitative data was analysed using SPSS, employing descriptive and non-parametric statistics. The Shapiro-Wilk test was employed to assess normality of distribution. Data was analysed using the chi ${ }^{2}$ test and Mann-Withney test, wherever applicable. A $p<0.05$ was considered significant. Missing data was excluded from statistical analysis.

Ethical approval and consent were not required for the study.

\section{Results}

Patients' characteristics are provided in Table 1.612 respondents took part in the study. The detailed characteristics of the participants were described in the first part of this research, which was published in Family Medicine \& Primary Care Review in 2017. Missing data was not considered in the statistics.
Some food products were regarded as potentially carcinogenic by $73.2 \%$ of all respondents ( $n=559$ ), while chemicals were regarded as potentially carcinogenic by $88.9 \%$ of the population. People with university education more frequently gave a positive answer to question concerning the carcinogenicity of food products $(76 \%$ vs $64.8 \%, p<0.05)$ and chemicals $(91.4 \%$ vs $82.1 \%, p<0.05)$. Among the chemicals which may cause the cancer, the following were listed: food additives (19.9\%), chemicals in tobacco products $(14.4 \%)$, benzene $(14 \%)$, asbestos $(10.8 \%)$, heavy metals $(9.6 \%)$ and others chemicals (20.1\%). Food additives were listed more often by female respondents $(14.9 \%$ vs $23 \% ; p<0.05)$, while men pointed out benzene (18.6\% vs $11.2 \% ; p<0.05)$.

\begin{tabular}{|l|l|l|}
\hline \multicolumn{3}{|l|}{ Table 1. Characteristics of the survey participants } \\
\hline Variable & $n$ & percentage [\%] \\
\hline Gender & & \\
male & 215 & 35.1 \\
female & 348 & 56.9 \\
missing data & 49 & 8.0 \\
\hline Age & & \\
$18-24$ & 21 & 3.4 \\
$25-49$ & 310 & 50.7 \\
$50-69$ & 202 & 33.0 \\
missing data & 79 & 12.9 \\
\hline Education & & \\
primary & 4 & 0.6 \\
secondary & 143 & 23.4 \\
university & 396 & 64.7 \\
missing data & 69 & 11.3 \\
\hline Smoking status & & \\
smoker & 119 & 19.4 \\
non-smoker & 423 & 69.1 \\
missing data & 70 & 11.5 \\
\hline Cancer family history & & \\
yes & 329 & 53.8 \\
no & 191 & 31.2 \\
missing data & 92 & 15.0 \\
\hline Vc Total & 612 & 100.0 \\
\hline
\end{tabular}

Any kind of physical activity may prevent cancer according to $58.6 \%$ of the population. There were slight differences between male and female opinions ( $57.1 \%$ vs $60.9 \%, p>0.05)$. The older respondents more often believed that physical activity may be a cancer prevention method than those aged 18-24 $(p>0.05)$. With regard to level of education, the differences were close to statistical significance, and more people with a university degree $(60.3 \%$ vs $51 \%)$ think that physical activity may play a preventive role $(p=0.057)$ (Table 2$)$.

Some vaccinations against viruses that cause cancer play a preventive role in the opinion of $40.4 \%$ of respondents, and nearly one-third $(31.2 \%)$ said it is hard to say. Women, more frequently than men, thought that immunisation can also prevent cancer ( $43.2 \%$ vs $35.8 \% ; p=0.059$ ). Differences close to statistical significance $(p=0.076)$ in various age groups $(33.3 \%$ vs $36.8 \%$ vs $48.5 \%$ ) were also observed (Table 3 ).

Smoking cigarettes is a well-known cancer risk factor, which was admitted by $97.2 \%$ of the respondents. Smokers made up one-fifth $(21.6 \%)$ of our population. Respondents said that smoking causes lung cancer (88.8\%), cancer of the larynx (39.1\%), oropharyngeal cancer (16.5\%) and others. Second-hand smoke exposure in the workplace was reported by $18.3 \%$ of the respondents, more often by those with secondary education than those with a university degree (28.6\% vs $14.7 \%$, $p<0.05)$. Second-hand smoke exposure was strongly connected with age, and the older the person, the more often smoke exposure was reported $(4.8 \%$ vs $16 \%$ vs $22 \%, p<0.05)$. 


\begin{tabular}{|c|c|c|c|c|c|c|c|c|c|c|}
\hline \multirow{2}{*}{$\begin{array}{l}\text { Can physical activity } \\
\text { prevent cancer? }\end{array}$} & \multicolumn{2}{|c|}{ Gender (\%) } & \multirow[t]{2}{*}{$p$} & \multicolumn{3}{|c|}{ Age (\%) } & \multirow[t]{2}{*}{$p$} & \multicolumn{2}{|c|}{ Education* (\%) } & \multirow[t]{2}{*}{$p$} \\
\hline & $F$ & $M$ & & $18-24$ & $25-49$ & $50-69$ & & Sec. & Univ. & \\
\hline Yes & 57.1 & 60.9 & \multirow{3}{*}{$>0.05$} & 47.6 & 58.1 & 59.4 & \multirow{3}{*}{$>0.05$} & 51.0 & 60.3 & \multirow{3}{*}{0.057} \\
\hline No & 12.1 & 7.0 & & 9.5 & 11.3 & 7.9 & & 14.7 & 8.6 & \\
\hline Hard to say & 30.8 & 32.1 & & 42.9 & 30.6 & 32.7 & & 34.3 & 31.1 & \\
\hline
\end{tabular}

$\mathrm{M}$ - male, F - female, Sec. - secondary education, Univ. - university degree; * - due to the low number of respondents with primary education $(n=4)$, they were not used for these statistics. Statistical analysis: Shapiro-Wilk and chi $^{2}$ test. Missing data was not considered in the statistics.

\begin{tabular}{|c|c|c|c|c|c|c|c|c|c|}
\hline \multirow[t]{2}{*}{ Do vaccines prevent cancer? } & \multicolumn{2}{|c|}{ Gender (\%) } & \multirow[t]{2}{*}{$p$} & \multicolumn{3}{|c|}{ Age (\%) } & \multirow[t]{2}{*}{$p$} & \multicolumn{2}{|c|}{ Education* (\%) } \\
\hline & $F$ & M & & $18-24$ & $25-49$ & $50-69$ & & Sec. & Univ. \\
\hline Yes & 43.2 & 35.8 & \multirow{3}{*}{0.059} & 33.3 & 36.8 & 48.5 & \multirow{3}{*}{0.076} & 41.9 & 41.2 \\
\hline No & 24.9 & 34.0 & & 38.1 & 31.3 & 23.0 & & 26.2 & 28.8 \\
\hline Hard to say & 31.9 & 30.2 & & 28.6 & 31.9 & 28.5 & & 31.9 & 30.0 \\
\hline
\end{tabular}

M - male, F - female, Sec. - secondary education, Univ. - university degree; ${ }^{*}$ - due to the low number of respondents with primary education $(n=4)$, they were not used for these statistics. Statistical analysis: Shapiro-Wilk and chi ${ }^{2}$ test. Missing data wewasre not considered in the statistics.

\begin{tabular}{|c|c|c|c|c|c|c|c|c|c|c|}
\hline \multirow{2}{*}{$\begin{array}{l}\text { Second-hand smoke } \\
\text { exposure at work }\end{array}$} & \multicolumn{2}{|c|}{ Gender (\%) } & \multirow[t]{2}{*}{$p$} & \multicolumn{3}{|c|}{ Age $n(\%)$} & \multirow[t]{2}{*}{$p$} & \multicolumn{2}{|c|}{ Education* (\%) } & \multirow[t]{2}{*}{$p$} \\
\hline & $F$ & $M$ & & $18-24$ & $25-49$ & $50-69$ & & Sec. & Univ. & \\
\hline Yes & 17.3 & 19.9 & \multirow{3}{*}{$>0.05$} & 4.8 & 16.0 & 22.0 & \multirow{3}{*}{0.0039} & 28.6 & 14.7 & \multirow{3}{*}{0.0002} \\
\hline No & 81.2 & 77.7 & & 80.9 & 82.4 & 77.0 & & 67.8 & 84.0 & \\
\hline Hard to say & 1.5 & 2.4 & & 14.3 & 1.6 & 1.0 & & 3.6 & 1.3 & \\
\hline
\end{tabular}

M - male, F - female, Sec. - secondary education, Univ. - university degree; ${ }^{*}$ - due to the low number of respondents with primary education $(n=4)$, they were not used for these statistics. Statistical analysis: Shapiro-Wilk and chi ${ }^{2}$ test. Missing data was not considered in the statistics.

Artificial UV light, such as sunbeds, were visited by almost two-thirds of all women (66.1\%), usually once every two or three years $(40 \%)$ or once a year $(16.7 \%)$.

\section{Discussion}

There are several effective primary cancer prevention methods. Some of them, like reduced tobacco use, are well known in the population, and others are usually not directly linked with cancer protection, such as vaccinations, and some recommendations, e.g. regular physical activity, have poor adherence. Prevention and a patient's education are the major tasks of GPs in their everyday work. Vaccinations are one of the primary successes of medicine, but they are becoming a great challenge for all healthcare professionals nowadays.

In literature, there are only a few similar studies investigating a patient's knowledge of such cancer prevention methods. There are some mentioned below that focus on each method separately.

According to the results of our survey, some vaccinations against viruses may prevent cancer in the opinion of approximately $40 \%$ of respondents, and nearly one-third (31.2\%) of them said it is hard to say. The oncogenic potential of viruses, such as HPV, HBV, hepatitis $\mathrm{C}$ virus (HCV), human herpesvirus 8 (HHV8) and Merkel, is well known, and an increased risk of cancer is expected in some individuals who experience these infections [18]. In literature, there are multiple studies evaluating the knowledge and acceptability of the HPV vaccine, which is new and, in many countries, not available for free. A Chinese study [19] provided the first insight into HPV awareness and attitudes towards the HPV vaccine among women. It showed that only $29 \%$ of the respondents had heard of HPV, and few knew that it is associated with cervical cancer. In a Polish survey, almost half of 450 parents of high school students who participated in the study (44.7\%) had never heard of HPV [20]. Regarding parents' attitudes toward HPV, 92\% stated that vaccines are effective in disease prevention, and $43.1 \%$ were concerned about the possible side effects of vaccination.

It is well known that regular physical activity is recommended and necessary to prevent obesity, cardiovascular diseases and to maintain a good overall health condition in old age. Multiple research has also shown that physical activity can be regarded as one cancer prevention method in particular cases. Increased levels of leisure-time physical activity were associated with lower risks for 13 of the 26 cancers investigated in current international original research conducted on large cohorts of patients [21], extending our current evidence base beyond colon, breast and endometrial cancers [22]. Nearly $60 \%$ of our participants stated that physical activity may prevent cancer, but still almost one-third of respondents said it is hard to say. On the contrary, the vast majority $(90 \%)$ of Irish respondents agreed that remaining physically active throughout life greatly reduces cancer risk [23].

Centres for Disease Control and Prevention analysed data from the 2015 National Health Interview Survey (NHIS) Occupational Health Supplement to assess the prevalence of self-reported workplace second-hand tobacco smoke (SHS) exposure. In 2015, $19.9 \%$ of non-smoking workers reported exposure to SHS at work during the 12 months preceding the interview, and $10.1 \%$ reported frequent exposure (twice a week or more) [24]. Similarly to this report, second-hand smoke exposure in the workplace was self-reported by $18.3 \%$ of the respondents in our research. According to main sanitary inspectorate data, second-hand smoke exposure in a workplace has declined recently and remains at a level of $8 \%$ [25]. Taking into consideration the risks and consequences that may arise from the high level of secondhand smoke exposure in a workplace, there is still a lot to do to make this as low as possible.

The major limitation of our study was a lack of representativeness of the study population (in fact, it used the convenience sample). Due to the fact that it was mainly an Internet-based survey, there is some missing data that cannot be considered in statistical analysis. What is more, the results of our study are 
probably culture specific. However, good knowledge of cancer risk factors and proven prevention methods are demanded by the population. Not only GP's but all healthcare professionals still have a lot to do in this area.

\section{Conclusions}

In the face of rapid civilization development all over the world, increasing cancer incidences and the resultant mortality, the knowledge of certain cancer prevention methods and risk factors is necessary. Nearly one-third of the respondents in this study was not aware of the anti-cancer role of selected vaccinations. In times of the anti-vaccination movement, it is essential to educate patients and promote the use of all vaccines, even those not obligatory.
Awareness of potentially carcinogenic food products and chemicals was high among our respondents. Female respondents pointed out food additives, whereas all participants listed chemicals in tobacco products, benzene, asbestos, heavy metals and others.

Physical activity was regarded as an effective prevention method, but in a majority of cases, this not directly linked with cancer prophylaxis. To the contrary, tobacco smoking was a well-known cancer risk factor among the respondents. Despite this fact, second-hand smoke exposure in the workplace was reported by almost $20 \%$ of the respondents and still remains a great challenge for employers in Poland.

All these findings are of practical usefulness for public health campaigns and may inspire general practitioners to provide relevant education to their patients.

Source of funding: This work was funded from the authors' own resources.

Conflicts of interest: The authors declare no conflicts of interest.

\section{References}

1. Bray F, Freddie J, Soerjomataram I, et al. Global cancer statistics 2018: GLOBOCAN estimates of incidence and mortality worldwide for 36 cancers in 185 countries. CA Cancer J Clin 2018; 68(6): 394-424.

2. United Nations, Department of Economic and Social Affairs Population Dynamics. World Population Prospects 2015 [cited 20.07.2019]. Available from URL: https://population.un.org/wpp/.

3. Wojciechowska U, Didkowska J. Zachorowania i zgony na nowotwory złośliwe w Polsce. Krajowy Rejestr Nowotworów, Centrum Onkologii - Instytut im. Marii Skłodowskiej-Curie [cited 20.07.2019]. Available from URL: http://onkologia.org.pl/raporty/ (in Polish).

4. WHO. Global Health and Aging [cited 20.07.2019]. Available from URL: https://www.who.int/ageing/publications/global_health.pdf.

5. Ferlay J, Colombet M, Soerjomataram I, et al. Estimating the global cancer incidence and mortality in 2018: GLOBOCAN sources and methods. IJC 2019; 144(8): 1941-1953.

6. Wallace RB. Primary prevention. In: Breslow L, Cengage G, edrs. Encyclopedia of Public Health [online] 2006. [cited 20.02.2019]. Available from URL: http://www.enotes.com/public-health- encyclopedia/primary-prevention.

7. Hussain A, Ali S, Ahmed M, et al. The anti-vaccination movement: a regression in modern medicine. Cureus 2018; 10(7): e2919, doi: 10.7759/cureus.2919.0.

8. Tsai HJ. Clinical cancer chemoprevention: from the hepatitis B virus (HBV) vaccine to the human papillomavirus (HPV) vaccine. Taiwan J Obstet Gynecol 2015; 54(2): 112-115.

9. Ferlay J, Ervik M, Lam F, et al. Global Cancer Observatory: Cancer today. Lyon, France: International Agency for Research on Cancer; 2018 [cited 20.07.2019]. Available from URL: https://gco.iarc.fr/today.

10. Ferlay J, Soerjomataram I, Dikshit R, et al. Cancer incidence and mortality worldwide: sources, methods and major patterns in GLOBOCAN 2012. Int J Cancer 2015; 136: 359-386.

11. Jeronimo J, Castle PE, Temin S, et al. Secondary prevention of cervical cancer: ASCO resource-stratified clinical practice guideline. $J$ Glob Oncol 2016; 3(5): 635-657; doi: 10.1200/JGO.2016.006577.

12. Simms KT, Steinberg J, Caruana M, et al. Impact of scaled up human papillomavirus vaccination and cervical screening and the potential for global elimination of cervical cancer in 181 countries, 2020-99: a modelling study. Lancet Oncology 2019; 20(3): 394-407.

13. Von Karsa L, Arbyn A, De Vuyst H, et al. European guidelines for quality assurance in cervical cancer screening. 2nd ed. Luxembourg: Office for Official Publications of the European Union; 2015: executive summary; pp. XIII-XXIV; supplements.

14. Basu P, Meheus F, Chami Y, et al. Management algorithms for cervical cancer screening and precancer treatment for resource-limited settings. Int J Gynecol Obstet 2017; 138: 26-32, doi: 10.1002/ijgo.12183.

15. Chrysostomou AC, Stylianou DC, Constantinidou A, et al. Cervical cancer screening programs in Europe: the transition towards HPV vaccination and population-based HPV testing. Viruses 2018; 10(12): E729, doi: 10.3390/v10120729.

16. NFZ. Programy profilaktyczne [cited 21.07.2019]. Available from URL: http://www.nfz.gov.pl/dla-pacjenta/programy-profilaktyczne/ (in Polish).

17. McTiernan, A, Friedenreich CM, Katzmarzyk PT, et al. physical activity in cancer prevention and survival: a systematic review. Med Sci Sports Exerc 2019; 51(6): 1252-1261.

18. Finn OJ. Vaccines for cancer prevention: a practical and feasible approach to the cancer epidemic. Cancer Immunol Res 2014; 2(8): 708-713, doi: 10.1158/2326-6066.CIR-14-0110.

19. He J, He L. Knowledge of HPV and acceptability of HPV vaccine among women in western China: a cross-sectional survey. BMC Women's Health 2018; 18(1): 130, doi: 10.1186/s12905-018-0619-8.

20. Ganczak, M, Owsianka B, Korzeń M. Factors that predict parental willingness to have their children vaccinated against HPV in a country with low HPV vaccination coverage. Int J Environ Res Public Health 2018; 15(4): 645, doi: 10.3390/ijerph15040645.

21. Moore C, I-Min Lee, Weiderpass E, et al. Association of leisure-time physical activity with risk of 26 types of cancer in 1.44 million adults. JAMA Intern Med 2016; 176(6): 816-825.

22. Leitzmann M, Powers H, Anderson AS, et al. European Code against Cancer 4th Edition: Physical activity and cancer. Cancer Epidemiol 2015; 39: S46-S55.

23. Ryan AM, Cushen S, Schellekens $\mathrm{H}$, et al. Poor awareness of risk factors for cancer in Irish adults: results of a large survey and review of the literature. Oncologist 2015; 20(4): 372-378, doi: 10.1634/theoncologist.2014-0453.

24. Su C, Syamlal G, Tamers S, et al. Workplace secondhand tobacco smoke exposure among U.S. non smoking workers, 2015. Morb Mortal Wkly Rep 2019; 68: 604-607, doi: http://dx.doi.org/10.15585/mmwr.mm6827a2.

25. Postawy Polaków wobec palenia tytoniu - GIS. Available from URL: https://gis.gov.pl/wp-content/uploads/2018/04/PostawyPolak\%C3\%B3w-do-palenia-tytoniu-Raport-2017.pdf. 
Tables: 4

Figures: 0

References: 25

Received: 22.07.2019

Reviewed: 16.08.2019

Accepted: 25.09.2019

Address for correspondence:

Marta Kurczewska-Michalak, MD

Zakład Medycyny Rodzinnej UM

ul. Narutowicza 60

90-136 Łódź

Polska

Tel.: + 4842 678-72-10

E-mail: m.kurczewska@o2.pl 